Compensatory Cross-Modal Effects of Sentence Context on Visual Word Recognition in Adults

Catherine Clark, Sara Guediche and Marie Lallier

BCBL. Basque Centre on Cognition, Brain and Language.

University of the Basque Country UPV/EHU.

Author Note:

BCBL. Basque Center on Cognition, Brain and Language, Donostia-San Sebastian, ES

This research is supported by the Basque Government through the BERC 2018-2021 program; the Spanish State Research Agency through BCBL Severo Ochoa excellence accreditation (SEV-20150490); the "Programa Estatal de Promoción del Talento y su Empleabilidad en I+D+i" fellowship, reference number: PRE2018-083945" to C.C; funding from European Union's Horizon 2020 Marie

Sklodowska-Curie grant agreement No-79954 to S.G.; and the grant PSI2015-6533-P from the Spanish Ministry of Economy, Industry and Competitiveness to M.L..

The authors declared no conflicts of interest regarding authorship and publication of this article.

Corresponding author: Catherine Clark, cclark@bcbl.eu 


\title{
Compensatory cross-modal effects of sentence context on visual word recognition in adults
}

\begin{abstract}
Reading involves mapping combinations of a learned visual code (letters) onto meaning. Previous studies have shown that when visual word recognition is challenged by visual degradation, one way to mitigate these negative effects is to provide "top-down" contextual support through a written congruent sentence context. Crowding is a naturally occurring visual phenomenon that impairs object recognition and also affects the recognition of written stimuli during reading. Thus, access to a supporting semantic context via a written text is vulnerable to the detrimental impact of crowding on letters and words. Here, we suggest that an auditory sentence context may provide an alternative source of semantic information that is not influenced by crowding, thus providing "top-down" support cross-modally. The goal of the current study was to investigate whether adult readers can cross-modally compensate for crowding in visual word recognition using an auditory sentence context. The results show a significant cross-modal interaction between the congruency of the auditory sentence context and visual crowding, suggesting that interactions can occur across multiple levels of processing and across different modalities to support reading processes. These findings highlight the need for reading models to specify in greater detail how top-down, crossmodal and interactive mechanisms may allow readers to compensate for deficiencies at early stages of visual processing.
\end{abstract}

Key words: auditory sentence context, crowding, lexical decision, orthographic processing, word recognition. 
Proficient reading relies on converting an arbitrary written code into a meaningful message by accessing semantic representations which were originally learned via spoken language. Processes in reading can be challenged by different characteristics of the written code. For example, the visual quality of a word affects relatively early stages of the mapping process and these effects can propagate through and hinder later stages in reading, such as visual word recognition and comprehension (Becker \& Killion, 1977; Meyer, Schvaneveldt \& Ruddy, 1975). The negative impact of degraded visual quality on word recognition can be mitigated by a preceding written sentence context (e.g., Stanovich \& West, 1979). However, when the visual characteristics of a written input hinder bottom-up processing, an alternative route, such as auditory input, could bypass any obstacles to semantic access. The current study tests whether a meaningful auditory sentence context can cross-modally mitigate negative effects of crowding on visual word recognition in skilled adult readers.

Crowding is a visual phenomenon that impairs visual processing (Levi, 2008). Broadly speaking, crowding effects refer to the difficulty in recognizing a target object in clutter (for review, see: Pelli, Palomares \& Majaj, 2004: Whitney \& Levi, 2011). Crowded stimulus conditions have resulted in poorer performance on letter identification and other perceptual tasks, and impair letter encoding (Bouma, 1970; Grainger, Tydgat \& Isselé, 2010; Jeon et al., 2010; Moll \& Jones, 2013; Montani, Facoetti \& Zorzi, 2015; Perea \& Gómez, 2012). According to Grainger and colleagues (2010), crowding effects on letter identification occur when letters are too close together because the features of neighbouring letters interfere with successful recognition of the target letter. In most written words, some letters are always surrounded by neighbouring letters. Therefore, certain letters in a string will be more crowded than others (Grainger, Dufau \& Ziegler, 2016) making this phenomenon naturally prevalent in reading. Crowding also affects word recognition; in one study, decreased letter spacing compared to standard letter spacing impaired visual word recognition in a lexical decision task (Montani et al., 2015; see also: Perea \& Gómez, 2012). The current study takes advantage of the decreased letter spacing manipulation to induce an ecologically plausible effect of crowding on visual word recognition, and explore interactions between the bottom-up processing of 
written words and higher-level semantic information provided by a congruent auditory sentence context.

Although reading by its very nature demands visual analysis of a written input, we may not rely on it exclusively for word recognition. There is extensive behavioural evidence showing that visual word recognition is facilitated when the target word is preceded by a semantically-related prime word (Becker, 1979; Becker, 1980; Becker \& Killion, 1977; Meyer et al., 1975) or a semantically congruent sentence (Fischler \& Bloom, 1979; Kleiman, 1980; Schuberth \& Eimas, 1977; Schuberth, Spoehr \& Lane, 1981; Stanovich \& West, 1979). Crucially, written semantic context has been shown to have an even greater facilitation effect when words are degraded by visual masking or decreased visual intensity of stimuli compared to when they are clearly presented (Becker \& Killion, 1977; Meyer et al., 1975; Stanovich \& West, 1979). Furthermore, auditory semantic context has been shown to attenuate effects of a comparatively higher-level manipulation such as orthographic regularity in English (Nation \& Snowling, 1998). Nation and Snowling (1998) found a greater benefit of an auditory sentence context for words that children find difficult to read (words with uncommon spelling, e.g., hymn, beige, canoe) compared to words they find easy to read (words with regular spelling rules, e.g., brave, cave, gave). Although their results suggest that semantic information can be accessed via the auditory modality to support orthographic processing in English, whether these cross-modal effects extend across languages and to lower-level visual manipulations (impairing bottom-up processing of letters and words) is not known. If they do, this would have implications for models of reading that do not consider the impact of the semantic input modality on reading processes.

The Interactive-Compensatory theory of reading (Perfetti \& Roth, 1981; Stanovich, 1984) emphasizes a compensatory mechanism in which deficiencies at one lower-level of processing (e.g., visual noise) can be offset by greater reliance on information from other (higher-level) stages of processing, such as semantic information. In many reading models, this compensatory mechanism has been implemented through interactions between different levels whereby more abstract sources of information, such as meaning, can influence lower-level processes during visual word 
recognition (e.g., Interactive Activation models: Coltheart, Rastle, Perry, Langdon \& Ziegler, 2001; Davis, 2010; Grainger \& Ferrand, 1994; Harm \& Seidenberg, 2004; McClelland \& Rumelhart, 1981; Perry, Ziegler \& Zorzi, 2006; 2010; Rumelhart \& McClelland, 1982). Although reading is an inherently cross-modal process involving mapping a written language onto spoken language, only a few reading models have incorporated cross-modal auditory-visual effects (e.g., see the Bimodal Interactive Activation Model: Diependaele, Ziegler \& Grainger, 2010; Grainger \& Ferrand, 1994), and account for the influence of phonology on orthographic processing (e.g., Grainger \& Ferrand, 1994; Lesch \& Pollatsek, 1993; Van Orden, 1987). These models have focused on the influence of an identical phonological prime on its corresponding orthographic representation, but they do not incorporate higher-level sentence context effects on sub-lexical and lexical orthographic processing. Crucially, the reading models that account for semantic context effects on lower-level reading processes do not specify the sensory modality of the semantic information and its potential importance. For example, a reader with immature or compromised orthographic processing skills, such as a beginner or poor reader, cannot easily access semantic context via a written input. However, they might be able to access a meaningful semantic context if it is presented via an alternative route, such as through auditory input. In this case, specifying the modality of semantic input, for example in interactive reading models, could reveal cross-modal interactions between higher-level and lower-level processes that may differ from visual semantic input. Models that specify input modality could then make better predictions regarding compensatory mechanisms according to semantic input modality, reading development and reading skill.

In the current experiment, we manipulated crowdedness of a written target word using standard versus decreased letter spacing, and the congruency of a preceding auditory sentence context using congruent versus incongruent sentence contexts. We predicted that the negative effects of crowding would be compensated for by greater use of a congruent auditory sentence context compared to an incongruent sentence context, showing a smaller effect of crowding on words in the congruent condition. Crowding effects and semantic context effects have been shown to vary with reading ability; for example, dyslexic readers are more vulnerable to crowding effects 
(Gori \& Facoetti, 2015; Moll \& Jones, 2011), and poorer readers rely on semantic context more than skilled readers (Perfetti \& Roth, 1981; Simpson, Lorsbach \& Whitehouse, 1983; Stanovich, 1980; Steen-Baker et al., 2017). Therefore, in a secondary analysis, we examined correlations between individual differences in reading fluency with sentence context and crowding effects in the sample of typical adult readers. While it is not clear whether typical readers would exhibit such correlations, based on the evidence cited above, we predicted a negative correlation with poorer readers showing a bigger influence of sentence context on crowding effects during visual word recognition as compared to more skilled readers.

\section{Materials and Methods}

\section{Participants}

Fifty Spanish-Basque adults took part in the study. One participant was excluded, due to a technical issue and failure to follow instructions, leaving a total of 49 subjects in the analysis (35 women, $M$ : 23.6 years, $S D: 3.5$ years). Participants were recruited using a database of users who live in the Basque Country, in Northern Spain. As the Basque Country is a bilingual region of Spain, with both Spanish and Basque as official languages, participants' level of Spanish was controlled for using their BEST score out of 65 (M: 64.8, SD: 0.7) (De Bruin, Carreiras \& Duñabeitia, 2017). The BEST score here is the number of targets named correctly out of 65 in a Spanish picture naming task and correlates with other measures of language proficiency. This measure was carried out when participants signed up to be part of the centre's participant pool and ensured that all subjects recruited for the present study were native-level Spanish speakers. In this region of Spain many people grow up speaking Basque and Spanish, as well as learning English in school. BEST stands for Basque, English and Spanish Tests and is a set of tasks developed to assess the language skills of multilingual adults in the Basque Country. All participants reported normal or corrected to normal vision and audition, and no reading impairment. All participants signed consent forms and the experiment was approved by [name deleted to maintain the integrity of the review process] and complied with the guidelines of the Helsinki Declaration. 


\section{Stimuli}

Target words. A list of 264 Spanish target words was created. These were nouns controlled for frequency $(M: 3.78, S D$ : 0.52 , range: $2.63-5.31)$ using the log count function on the EsPal database (Duchon, Perea, Sebastián-Gallés Martí, \& Carreiras, 2013), and length (M: 5.24, SD: 0.73 , range: 4-6 letters). Pseudowords were created from the same list of words by replacing two letters. They were all orthographically legal in Spanish, the first letter was always changed, and word length was maintained. Target words (for example: ruedas) and pseudowords (for example: vuebas) were presented in black on an off-white background in Times New Roman font, size 28pt. The degree of crowding (uncrowded versus crowded) was manipulated by using standard letter spacing (0.0) and decreased letter spacing (-3.5) settings in Microsoft Office (See Figure 1). The visual angle of target words and pseudowords was approximately $2.9^{\circ}$ to $4^{\circ}$ for uncrowded targets with standard letter spacing, and $2.1^{\circ}$ to $3.4^{\circ}$ for crowded targets with decreased letter spacing.

[Figure 1 here]

Auditory sentence contexts. 264 Spanish congruent auditory sentences based on the target words were created. Target words always appeared at the end of the sentence. To create an incongruent sentence condition, sentences were first put into pairs at random, and final target words were swapped. Sentence pairs were then reviewed and edited to ensure that incongruent target words matched the penultimate word in the sentence for gender and number, in this way ensuring that sentences were still grammatically legal but semantically incongruent. This resulted in a total of 528 sentence/target word combinations (see Table 1 for example).

[Table 1 here]

The 528 sentence combinations were rated using a Likert scale for semantic congruence of the target word by 10 adult, native Spanish speakers who did not participate in the main experiment. The participants were asked to rate the sentences based on the probability that the final word was a likely continuation of the sentence: 0 (very improbable) to 7 (very probable). Any congruent sentences with less than $80 \%$ of responses rated at 6 or 7 , or with a mean of less than 6 , were excluded. Any incongruent sentences with mean ratings above 3 were excluded. This resulted in a 
total of 216 sentences that could be either congruent or incongruent in relation to the target word. The sentences were then recorded without the sentence final target word by a female native Spanish speaker using a Marantz Professional PMD 671 Recorder. Sentence contexts were trimmed and had a similar duration $(\mathrm{M}=1853 \mathrm{~ms}, S D=301 \mathrm{~ms})$.

We employed two different Lexical Decision Tasks (LDTs): The LDT-no context was designed to assess the effect of our crowding manipulation on isolated words. The task was a 2 x 2 factorial design with Lexicality (word, pseudoword) and Crowding (uncrowded, crowded) manipulated as within-subject factors. There were 54 trials per condition. The LDT-auditory context was designed to assess effects of an auditory sentence context on crowding in visual word recognition. Sentence context (congruent, incongruent), Crowding (uncrowded, crowded), and Lexicality (word, pseudoword) were manipulated. Analysis on data from the LDT-auditory context was conducted on the target word data only. Pseudowords were treated as filler items as they could not be coded by their semantic congruency with the preceding sentence context. Therefore, the LDT-auditory context was analysed as a 2 x 2 factorial design with Sentence context (congruent, incongruent) and Crowding (uncrowded, crowded) as within subject factors. There were eight conditions and 27 trials per condition.

Stimuli were presented in a random order and counterbalanced across participants, in both lexical decision tasks. Counterbalancing was implemented using a Latin square design across both tasks. Each target stimuli appeared in every condition, however, participants never heard a sentence context more than once nor did they see the same target word or pseudoword more than once.

Reading assessment texts. In order to assess reading ability in our sample, two texts were used to measure individual reading fluency in Spanish ${ }^{1}$. The first task (the meaningful text) assessed reading fluency with a contextually rich text that was the same as employed by Authors et al. (2016). It was a newspaper article about climate change. The second task (the meaningless text) was designed to be syntactically correct but not semantically coherent. It was a Spanish adaptation of the

${ }^{1}$ Two additional reading tasks were carried out using two short excerpts from newspaper articles. However, the texts were poorly matched on several factors, and one text also had some grammatical errors, we do not report any analyses including these texts. 
French Alouette reading test (Lefavrais, 1965). This text was used to assess mechanistic reading that cannot greatly rely on the support of semantics. Both texts were presented on A4 paper $(21 \mathrm{~cm}$ x $29.7 \mathrm{~cm})$.

\section{Procedure}

Participants were tested individually in an isolated behavioural testing cabin. They were seated approximately $50 \mathrm{~cm}$ away from the screen. First, participants completed two lexical decision tasks (LDT-no context and LDT-auditory sentence), the order of the tasks was counterbalanced across participants. Participants then completed the reading fluency tasks last.

LDT-no context. For the LDT-no context, participants were told that a word would appear in the centre of the screen and they should decide if this word was a real Spanish word or not. They responded with their index finger for a real word with one hand, and for a pseudoword with the other hand. Participants completed six practice trials, followed by the task. Each trial began with a fixation point that remained on the screen for $500 \mathrm{~ms}$ before it was replaced by the target stimulus. The stimulus remained on screen for $3000 \mathrm{~ms}$ or until the participant responded.

LDT-auditory context. In the LDT-auditory context participants were instructed that they would hear an auditory sentence through Sennheiser viewsonic headphones, and after each sentence a target stimulus would appear in the centre of the screen. They were asked to decide if this word was a real Spanish word or not. Participants were told that they should pay attention to the sentence they heard, but that the task was based on their decision about the written word. They responded in the same way as in the LDT-no context. Participants completed six practice trials, followed by the task. Each trial began with a fixation point while the auditory sentence was played. Once the sentence had finished, the fixation point was replaced by the target stimulus. The stimulus remained on screen for $3000 \mathrm{~ms}$ or until the participant responded.

Reading assessment. After the LDTs participants completed the reading assessments. For both tasks participants were asked to read the text aloud as quickly and accurately as they could for two minutes, while the researcher timed them and noted any errors. The number of accurate words 
per minute was recorded by the experimenter as the participants were reading. Participants always read the meaningful text first and the meaningless text second.

\section{Results}

\section{Data analyses}

Mean accuracy and reaction times for the LDT-no context and LDT-auditory context for each condition are reported in Table 2. Data were analysed using IBM SPSS for Windows, version 19 (IBM Corp., Armonk, N.Y., USA). The experiment itself excluded trials that were less than $150 \mathrm{~ms}$ or exceeded $3000 \mathrm{~ms}(0.22 \%$ of the data). In addition, across both tasks, incorrect responses (3.14\% of the data) and then outliers (4.8\% of the data) were removed from the analysis. Outliers were defined as any reaction time that was 2 standard deviations above or below the subject's mean for each condition. This left an average of 50 trials $(\min =37)$ per condition for the LDT-no context, and 25 trials $(\min =13)^{2}$ per condition for the LDT-auditory context, across participants and conditions. Overall, subjects performed at ceiling on both LDTs so error data was not submitted to analysis.

[Table 2 here]

\section{LDT-no context}

For the LDT-no context, data were submitted to a 2 Lexicality (Words, Pseudowords) x 2 Crowding (uncrowded, crowded) repeated measures ANOVA. Lexicality and Crowding were within subject factors. The analysis showed main effects of Lexicality, $F(1,48)=45.72, p<.001$, $\eta_{\mathrm{p}}{ }^{2}=.49$, and Crowding, $F(1,48)=18.73, p<.001, \eta_{\mathrm{p}}{ }^{2}=.28$. Participants responded to words $(M=$ $630.82, S E M=15.90)$ faster than pseudowords $(M=796.78, S E M=34.23)$, and to uncrowded stimuli $(M=703.99, S E M=24.22)$ faster than crowded stimuli $(M=723.61, S E M=23.38)($ See Figure 2). There was no significant interaction between the two factors of interest: Lexicality and Crowding.

[Figure 2 here]

\section{LDT-auditory context}

${ }^{2}$ One subject had an accuracy rate of less than $60 \%$ in the incongruent sentence condition for words in the LDT-auditory context. 
For the LDT-auditory context ANOVAs were conducted on word data only. Pseudowords were used as filler items in the task.

Word data were submitted to a 2 Sentence context (congruent, incongruent) x 2 Crowding (uncrowded, crowded) repeated measures ANOVA. Sentence context and Crowding were within subject factors. The analysis showed a main effect of Sentence context, $F(1,48)=238.49, p<.001$,

$\eta_{\mathrm{p}}{ }^{2}=.83$. Responses for words preceded by a congruent sentence $(M=545.38, S E M=12.86)$ were faster than for words preceded by an incongruent sentence $(M=658.54, S E M=16.42)$. There was also a main effect of Crowding, $F(1,48)=41.88, p<.001, \eta_{\mathrm{p}}{ }^{2}=.47$, with faster response times to uncrowded words $(M=586.84, S E M=14.53)$ compared to crowded words $(M=617.09, S E M=$ 14.42). As we had predicted, the interaction between Sentence context and Crowding was significant, $F(1,48)=4.83, p=.033, \eta_{\mathrm{p}}{ }^{2}=.09$ (See Figure 3 ). Post-hoc pairwise comparisons showed that the effect of crowding was smaller for words presented after a congruent auditory sentence context (mean difference $=22.41, S E M=4.53, p<.001$ ), than after an incongruent auditory sentence context (mean difference $=38.10, S E M=6.98, p<.001$ ).

[Figure 3 here]

\section{Correlations with reading fluency}

Given previous reports that effects of crowding or semantic context may vary according to reading skill (e.g., poor readers and dyslexics), we examined the relationship between reading fluency and effects of crowding on the LDT-no context, and the Sentence context by Crowding interaction on the LDT-auditory context. Reading fluency scores based on accurate words per minute, for two the reading tasks (meaningful and meaningless texts), are reported in Table 3. As shown in Figure 4, our sample was normally distributed (Shapiro-Wilk test: meaningful text, W(48) $=.99, p=.10$, and meaningless text, $W(48)=.97, p=.27$ and was made up of proficient adult readers.

[Table 3 here]

[Figure 4 here] 
The effect of crowding on the LDT-no context was calculated as the difference between each subject's mean reaction times for crowded and uncrowded stimuli. This calculation was collapsed across words and pseudowords, as there was no interaction between Lexicality and Crowding (See Figure 2). Positive values indicated the size of the crowding effect (slower reaction times for crowded compared to uncrowded stimuli) on reaction times. Negative values indicated the opposite effect. Values closer to zero indicated little difference between crowded and uncrowded conditions. Reading task scores were calculated using the number of accurate words read per minute. Correlation analyses were conducted separately on the meaningful text and the meaningless text. We expected a negative correlation between reading scores and the effect of crowding, with poorer readers showing a bigger crowding effect than more skilled readers. As data did not meet the assumption of linearity we used the non-parametric Spearman's rank correlation analysis. The correlation between the effect of crowding on visual word recognition and reading fluency scores for the meaningful text, $r_{s}(47)=-0.02, p=.88$, or meaningless text, $r_{s}(47)=-0.01, p=.92$ were not significant.

For the LDT-auditory context, the effect of Sentence context on Crowding was calculated to reflect the Crowding by Sentence context interaction found in this task. We used subjects' mean reaction times on word data and subtracted the crowding effect in the congruent sentence condition, from crowding effect in the incongruent sentence condition. Positive values indicated that reaction times were slowed by crowding more in the incongruent sentence condition, and were slowed to a lesser extent by crowding in the congruent sentence condition. Negative values indicated the opposite effect. Values closer to zero indicated little difference in the effect of crowding between incongruent and congruent sentence conditions. Reading fluency scores were calculated using the number of accurate words read per minute. Separate correlation analyses were conducted for the meaningful text and the meaningless text. We expected a negative correlation between reading scores and the effect of an auditory sentence context on crowding, with poorer readers showing a bigger interaction effect than skilled readers. The data did not meet the assumption of linearity so we used a Spearman's rank correlation analysis. There was no significant relationship between the 
effect of Sentence context on Crowding and reading fluency on the meaningful text, $r_{s}(47)=-0.11$, $p=.47$, or the meaningless text, $r_{s}(47)=-0.02, p=.89$.

\section{Discussion}

The present study aimed to investigate whether an auditory sentence could provide an alternative route to semantic information when orthographic processing is compromised. To this end, we manipulated the crowdedness (decreased versus standard letter spacing) of written stimuli as a way of impairing orthographic processing, and the congruency of an auditory sentence context to provide meaningful (as compared to meaningless) semantic information. Two lexical decision tasks were performed. In one task, to first assess effects of crowding independent of the context, words and pseudowords were presented in isolation (LDT-no context). In the other task, we manipulated an additional factor, the congruency of a preceding auditory sentence context (LDTauditory context).

As expected, both tasks showed a main effect of crowding on visual word recognition. Lexical decisions were impaired with slower reaction times for crowded compared to uncrowded words. The consensus, in the context of reading, is that crowding effects emerge at a relatively early stage (Bouma, 1970; Montani et al., 2015; Pelli et al., 2004; Perea \& Gómez, 2012) impairing feature integration of letters (Grainger et al., 2010) and propagating through the reading pathway to affect word recognition (Montani et al., 2015; Perea \& Gómez, 2012; Snell, van Leipsig, Grainger \& Meeter, 2018). In the LDT-no context, we did not find a significant Lexicality by Crowding interaction as we might have expected given prior claims that crowding effects may depend on lexicality (Montani et al., 2015; Perea \& Gómez, 2012). It is not clear whether differences in experimental design, difficulty of the crowding manipulation, sample size (larger than prior studies), or analysis procedures contributed to differences across studies. However, we were not concerned by lexical-specific effects, as our primary interest was to implement a successful crowding manipulation that impaired isolated word recognition. Most importantly for the current study, the crowding manipulation did impair word recognition, and therefore allowed us to further investigate cross-modal interactions with auditory sentence context effects. 
In the cross-modal lexical decision task (LDT-auditory context), we found a main effect of Sentence context showing faster lexical decisions for words that followed a congruent auditory sentence. This finding adds to previous work showing that a meaningful sentence context, compared to a meaningless sentence context, can support visual word recognition (Fischler \& Bloom; Kleiman, 1980; Schuberth \& Eimas, 1977; Schuberth et al., 1981; Stanovich \& West, 1979). It also builds upon other cross-modal semantic priming experiments (Carter, Hough, Stuart \& Rastatter, 2011; Holcomb \& Anderson, 1993), and studies investigating lexical ambiguity and lexical access using auditory sentence contexts (Onifer \& Swinney, 1981; Seidenberg, Tanenhaus, Leiman \& Bienkowski, 1982; Swinney, Onifer, Prather \& Hirshkowitz, 1979). More generally, the result reflects the cross-modal nature of language processing as illustrated by effects of phonology on visual word recognition (e.g., Lesch \& Pollatsek, 1993; Van Orden, 1987), and influences of orthography on spoken word recognition (e.g., Pattamadilok, Morais, Ventura \& Kolinsky, 2007; Ziegler \& Ferrand, 1998; Ziegler, Ferrand \& Montant, 2004). These studies highlight interactions between orthography and phonology in written and spoken language processing. However, they do not examine whether there may be modality-specific interactions between higher-level semantic information from an acoustic input and a purely visual manipulation during reading. Here, we show that the reciprocal relationship between written and spoken language can be taken advantage of by using higher-level semantic information to support bottom-up orthographic processing, across different representational levels.

Of particular interest was whether a congruent auditory sentence context could modulate the negative effects of crowding, a visual phenomenon that impairs orthographic processing. Notably, we found a Sentence context by Crowding interaction that shows for the first time a cross-modal modulatory effect of an auditory sentence context on a lower-level visual manipulation during visual word recognition. This result is consistent with studies illustrating the importance of a meaningful semantic context in resolving the challenges caused by a degraded bottom-up signal. Such interactions between top-down and bottom-up effects have been prevalent within the visual modality (Becker \& Killion, 1977; Meyer et al., 1975; Stanovich \& West, 1979), and within the 
auditory modality (Davis, Ford, Kherif \& Johnsrude, 2011; Guediche, Reilly, Santiago, Laurent \& Blumstein, 2016; Kalikow, Stevens \& Elliott, 1977; Obleser, Wise, Dresner \& Scott, 2007). However, the present result extends this research by showing that these interactive and modulatory effects also occur across modalities to support recognition of degraded visual stimuli during reading.

According to an interactive-compensatory view of reading (Perfetti \& Roth, 1981; Stanovich, 1984), one possible interpretation of the Sentence Context by Crowding interaction is greater reliance on semantic context to compensate for a deficiency at a lower processing level (i.e., excessive feature integration of letters caused by crowding). While this result is in line with the interactive aspect of many accounts of reading (e.g., Coltheart, Rastle, Perry, Langdon \& Ziegler, 2001; Davis, 2010; Grainger \& Ferrand, 1994; Harm \& Seidenberg, 2004; McClelland \& Rumelhart, 1981; Perry, Ziegler \& Zorzi, 2006; 2010; Rumelhart \& McClelland, 1982), our results highlight the need for reading models that incorporate sources of semantic context from different modalities. The current results suggest that when orthographic processing skills are compromised, readers can still access semantic information from the auditory modality and compensate for impaired orthographic processing in the visual modality. Importantly, semantic compensatory effects may differ according to the input modality because when orthographic processing is impaired, so is access to semantic context via a visually presented written input. This point is especially relevant to those who have an orthographic or visual processing deficit in the absence of more general language impairments. For example, dyslexic readers, who struggle to access meaning from an orthographic input, may be able to take advantage of meaningful context more readily when it is presented in the auditory modality and successfully compensate for visual deficits that affect early processes in reading (e.g., a visual attention span deficit: Bosse, Tainturier \& Valdois, 2007). The same could be true for beginner readers who have not yet developed the necessary orthographic processing skills to be able to efficiently access meaning from a written text. If reading models were to specify semantic input modality (visual or auditory), they could then predict 
compensatory effects of semantic context on lower-level reading processes as a function of input modality, reading development and reading profile.

How such cross-modal interactions should be instantiated in a computational or neurocomputational account of reading requires further investigation. Drawing on evidence from neuroimaging and behavioural studies (Booth et al., 2002; Carter, Hough, Stuart \& Rastatter, 2011; Holcombe \& Anderson, 1993), converging auditory and written semantic pathways (Binder, Desai, Graves \& Conant, 2009; Patterson, Nestor \& Rogers, 2007; Price, 2012) may provide an amodal source of top-down semantic feedback to modulate the bottom-up, orthographic and visual processes. A similar argument has been made for written sentence context effects in resolving lower-level acoustic phonetic ambiguities during auditory word recognition (Guediche et al., 2019). However, there are still many open questions regarding the nature of cross-modal and/or top-down bottom-up interactions. For example, are they a result of interactions between modality-specific pathways (Patterson, Nestor \& Rogers, 2007) or a combination of amodal and modality-specific regions (Patterson \& Lambon Ralph, 2016)? Does the interaction between higher-level semantic and lower-level visual information occur at later stages in the reading pathway (Carreiras, Armstrong, Perea \& Frost, 2014; Lau, Phillips \& Poeppel, 2008) when meaning is integrated with the degraded input? These questions have implications for developing a biologically accurate model of reading, as well as furthering our understanding of cross-modal and top-down bottom-up interactions in language processing more generally.

The cross-modal interaction effect also has implications for reading processes across languages. The current study examined the cross-modal effects of congruency of an auditory sentence context and visual crowding in Spanish, a transparent language. Our results show that, in a transparent orthography, an auditory sentence context can enhance lexical processing and speed up lexical decisions when visual word recognition is impaired due to a visual crowding manipulation. Nation and Snowling (1998) examined the effect of an auditory sentence context and word regularity in an opaque orthography (English). They found an interaction between the presence of an auditory sentence context and word regularity whereby contextual facilitation was greater for 
irregular compared to regular words. Their study showed that an auditory sentence context enhanced lexical processing (i.e., whole word reading) when orthographic processing was challenged by target word regularity. Taken together both studies suggest that the cross-modal and interactive effects of an auditory sentence context on visual word recognition may generalize across transparent and opaque orthographies, at least with respect to manipulations that impact orthographic processing and subsequent lexical access. However, as orthographic transparency can influence reading acquisition and reading strategies (Katz \& Feldman, 1983; Lallier, Carreiras, Tainturier, Savill \& Thierry, 2013; Ziegler \& Goswami, 2005), the Sentence context by Crowding interaction could differ across orthographies. Readers of transparent orthographies tend to rely more on sub-lexical reading strategies, while readers of opaque orthographies rely on larger orthographic chunks or whole word units (Ziegler \& Goswami, 2005). It is therefore possible that readers of transparent orthographies may be more vulnerable to crowding effects (Grainger et al., 2010). For this reason, they may show a greater compensatory effect of semantically-enhanced lexical processing to reduce the impact of crowding on target words. Thus, in comparison, the Sentence context by Crowding interaction would be attenuated for readers of an opaque orthography because they rely more heavily on lexical reading strategies, and the processing of larger orthographic units may not be as impaired by crowding. Importantly, we would also expect the interaction effect to depend on other task and participant characteristics that are known to modulate the use of lexical reading strategies and may impact reader vulnerability to crowding effects (e.g., LDT or word naming tasks, and different stages of reading development).

A limitation of the current study is that it cannot speak to the stage at which these interactive mechanisms may come into play, or the mechanism by which auditory semantic information influences bottom-up visual processes in reading. For example, does the interaction effect occur during an early processing stage that is vulnerable to crowding effects, such as feature integration of letters (Grainger et al., 2010), or is it the consequence of converging information, at later stages? The present result suggests that a meaningful auditory sentence provides higher-level semantic information that can modulate the impact of a deficiency in early visual processing during visual 
word recognition, compared to a meaningless context. However, when and how auditory semantic information influences lower-level processes affected by a visual manipulation, will require further investigation.

Finally, an exciting aspect of this result is that it may have implications for educational practice. The Sentence context by Crowding interaction shows that a congruent, compared to an incongruent, auditory context can help readers when compensating for an ecologically plausible effect in reading. The expected correlation between sentence context effects on crowding and individual variability in reading skill, in our sample of typical readers, was not significant. However, the present study focused on skilled adult readers who had little variability in reading fluency (See Figure 4.). Interestingly, the availability of sentence context has been shown to be especially beneficial to dyslexic readers (Nation and Snowling, 1998), who are particularly vulnerable to crowding effects (Bertoni et al., 2019; Gori \& Facoetti, 2015; Moll \& Jones, 2013). Therefore, those with specific reading impairments and atypical reading skills may find auditory semantic context especially helpful in accessing supporting semantic information, without having to face the inherent challenges involved in accessing meaning from a written text. Thus, the interaction effect found in the present study may be more relevant for those with severe reading difficulties, or even readers at the earlier stages of reading acquisition. Future studies that strive to answer these questions could have a real impact on educational and clinical practice. 


\section{Reference List}

Authors et al. (2016).

Becker, C. A. (1979). Semantic context and word frequency effects in visual word recognition. Journal of Experimental Psychology: Human Perception and Performance, 5, 252-259. doi:10.1037/0096-1523.5.2.252

Becker, C. A. (1980). Semantic context effects in visual word recognition: an analysis of semantic strategies. Memory \& Cognition, 8, 493-512. doi:10.3758/BF03213769

Becker, C. A., \& Killion, T. H. (1977). Interaction of visual and cognitive effects in word recognition. Journal of Experimental Psychology: Human Perception and Performance, 3, 389-401. doi:10.1037/0096-1523.3.3.389

Bertoni, S., Franceschini, S., Ronconi, L., Gori, S., \& Facoetti, A. (2019). Is excessive visual crowding causally linked to developmental dyslexia? Neuropsychologia, 130(April), 107117. doi:10.1016/j.neuropsychologia.2019.04.018

Binder, J. R., Desai, R. H., Graves, W. W., \& Conant, L. L. (2009). Where is the semantic system? A critical review and meta-analysis of 120 functional neuroimaging studies. Cerebral Cortex, 19, 2767-2796. doi:10.1093/cercor/bhp055

Booth, J. R., Burman, D. D., Meyer, J. R., Gitelman, D. R., Parrish, T. B., \& Mesulam, M. M. (2002). Modality independence of word comprehension. Human Brain Mapping, 16, 251261. doi:10.1002/hbm.10054

Bouma, H. (1970). Interaction effects in parafoveal letter recognition. Nature, 226, 177-178. doi:10.1038/226177a0

Bosse, M. L., Tainturier, M. J., \& Valdois, S. (2007). Developmental dyslexia: the visual attention span deficit hypothesis. Cognition, 104, 198-230. doi:10.1016/j.cognition.2006.05.009

Carreiras, M., Armstrong, B. C., Perea, M., \& Frost, R. (2014). The what, when, where, and how of visual word recognition. Trends in Cognitive Sciences, 18, 90-98. doi:10.1016/j.tics.2013.11.005 
Carter, M. D., Hough, M. S., Stuart, A., \& Rastatter, M. P. (2011). The effects of inter-stimulus interval and prime modality in a semantic priming task. Aphasiology, 25, 761-773. doi:10.1080/02687038.2010.539697

Coltheart, M., Rastle, K., Perry, C., Langdon, R., \& Ziegler, J. (2001). DRC: a dual route cascaded model of visual word recognition and reading aloud. Psychological Review, 108, 204-256. doi:10.1037/0033-295X.108.1.204

Davis, C. J. (2010). The spatial coding model of visual word identification. Psychological Review, 117, 713-758. doi:10.1037/a0019738

Davis, M. H., Ford, M. A., Kherif, F., \& Johnsrude, I. S. (2011). Does semantic context benefit speech understanding through "top-down" processes? Evidence from time-resolved sparse fMRI. Journal of Cognitive Neuroscience, 23, 3914-3932.doi:10.1162/jocn_a_00084

De Bruin, A., Carreiras, M., \& Duñabeitia, J. A. (2017). The BEST dataset of language proficiency. Frontiers in Psychology, 8. doi:10.3389/fpsyg.2017.00522

Diependaele, K., Ziegler, J. C., \& Grainger, J. (2010). Fast phonology and the bimodal interactive activation model. European Journal of Cognitive Psychology, 22, 764-778. doi:10.1080/09541440902834782

Duchon, A., Perea, M., Sebastián-Gallés, N., Martí, A., \& Carreiras, M. ( 2013). EsPal: one-stop shopping for Spanish word properties. Behavior Research Methods, 45, 1246-1258. doi:10.3758/s13428-013-0326-1

Fischler, I., \& Bloom, D. A. (1979). Automatic and attentional processes in the effects of sentence contexts on word recognition. Journal of Verbal Learning \& Verbal Behavior, 18, 1-20. doi:10.1016/S0022-5371(79)90534-6

Gori, S., \& Facoetti, A. (2015). How the visual aspects can be crucial in reading acquisition: the intriguing case of crowding and developmental dyslexia. Journal of Vision, 15(1). doi:10.1167/15.1.8

Grainger, J., Dufau, S., \& Ziegler, J. C. (2016). A vision of reading. Trends in Cognitive Sciences, 20, 171-179. doi:10.1016/j.tics.2015.12.008 
Grainger, J., \& Ferrand, L. (1994). Phonology and orthography in visual word recognition: effects of masked homophone primes. Journal of Memory and Language, 33, 218-233. doi:10.1006/jmla.1994.1011

Grainger, J., Tydgat, I., \& Isselé, J. (2010). Crowding affects letters and symbols differently. Journal of Experimental Psychology: Human Perception and Performance, 36, 673-688. doi:10.1037/a0016888

Guediche, S., Reilly, M., Santiago, C., Laurent, P., \& Blumstein, S. E. (2016). An fMRI study investigating effects of conceptually related sentences on the perception of degraded speech. Cortex, 79, 57-74. doi:10.1016/j.cortex.2016.03.014

Guediche, S., Zhu, Y., Minicucci, D., Blumstein, S., (2019) Written sentence context effects on acoustic-phonetic perception: fMRI reveals cross-modal semantic perceptual interactions. Brain and Language, 199, 104698. doi:10.1016/j.bandl.2019.104698

Harm, M. W., \& Seidenberg, M. S. (2004). Computing the meanings of words in reading: cooperative division of labor between visual and phonological processes. Psychological Review, 111, 662-720. doi:10.1037/0033-295X.111.3.662

Holcomb, P. J., \& Anderson, J. E. (1993). Cross-modal semantic priming: a time-course analysis using event-related brain potentials. Language and Cognitive Processes, 8, 379-411. doi:10.1080/01690969308407583

Jeon, S. T., Hamid, J., Maurer, D., \& Lewis, T. L. (2010). Developmental changes during childhood in single-letter acuity and its crowding by surrounding contours. Journal of Experimental Child Psychology, 107, 423-437. doi:10.1016/j.jecp.2010.05.009

Kalikow, D. N., Stevens, K. N., \& Elliott, L. L. (1977). Development of a test of speech intelligibility in noise using sentence materials with controlled word predictability. The Journal of the Acoustical Society of America. 61, 1337-1351. doi:10.1121/1.381436

Katz, L., \& Feldman, L. B. (1983). Relation between pronunciation and recognition of printed words in deep and shallow orthographies. Journal of Experimental Psychology: Learning, Memory, and Cognition, 9, 157-166. doi:10.1037/0278-7393.9.1.157 
Kleiman, G. M. (1980). Sentence frame contexts and lexical decisions: sentence-acceptability and word-relatedness effects. Memory \& Cognition, 8, 336-344. doi:10.3758/BF03198273

Lallier, M., Carreiras, M., Tainturier, M. J., Savill, N., \& Thierry, G. (2013). Orthographic transparency modulates the grain size of orthographic processing: behavioral and ERP evidence from bilingualism. Brain Research, 1505, 47-60. doi:10.1016/j.brainres.2013.02.018

Landerl, K., Wimmer, H., \& Frith, U. (1997). The impact of orthographic consistency on dyslexia: A German-English comparison. Cognition, 63, 315-334. doi:10.1016/S00100277(97)00005-X

Lau, E. F., Phillips, C., \& Poeppel, D. (2008). A cortical network for semantics: (de)constructing the N400. Nature Reviews Neuroscience, 9, 920-933. doi:10.1038/nrn2532

Lefavrais, P. (1965). Description, définition et mesure de la dyslexie. Utilisation du test "L'Alouette" [Description, definition and measurement of dyslexia. Use of the "Alouette" test]. Revue de Psychologie Appliquée, 15, 33-34.

Lesch, M. F., \& Pollatsek, A. (1993). Automatic access of semantic information by phonological codes in visual word recognition. Journal of Experimental Psychology: Learning, Memory, and Cognition, 19, 285-294. doi:10.1037/0278-7393.19.2.285

Levy, B. A. (1981). Interactive processes during reading. In A. Lesgold \& C. Perfetti (Eds.), Interactive processes in reading (pp. 269-297). Hillsdale, NJ: Erlbaum.

Levi, D. M. (2008). Crowding-an essential bottleneck for object recognition: a mini-review. Vision Research, 48, 635-654. doi:10.1016/j.visres.2007.12.009

Lukatela, G., \& Turvey, M. T. (1994). Visual lexical access is initially phonological: I. Evidence from associative priming by words, homophones, and pseudohomophones. Journal of Experimental Psychology: General, 123, 107-128. doi:10.1037//0096-3445.123.2.107

McClelland, J. L., \& Rumelhart, D. E. (1981). An interactive activation model of context effects in letter perception: part I. An account of basic findings. Psychological Review, 88, 375-407. doi:10.1037/0033-295X.88.5.375 
Meyer, D. E., Schvaneveldt, R. W. \& Ruddy, M. G. (1975). Loci of contextual effects on visual word-recognition. In P. M. A. Rabbitt \& S. Dornic (Eds.), Attention and Performance V (pp. 98-118). London, UK: Academic Press.

Moll, K., \& Jones, M. (2013). Naming fluency in dyslexic and nondyslexic readers: differential effects of visual crowding in foveal, parafoveal, and peripheral vision. Quarterly Journal of Experimental Psychology, 66, 2086-2091. doi:10.1080/17470218.2013.840852

Montani, V., Facoetti, A., \& Zorzi, M. (2015). The effect of decreased interletter spacing on orthographic processing. Psychonomic Bulletin \& Review, 22, 824-832. doi:10.3758/s13423-014-0728-9

Nation, K., \& Snowling, M. J. (1998). Individual differences in contextual facilitation: evidence from dyslexia and poor reading comprehension. Child Development, 69, 996-1011. doi:10.1111/j.1467-8624.1998.tb06157.x

Obleser, J., Wise, R. J. S., Dresner, M. A., \& Scott, S. K. (2007). Functional integration across brain regions improves speech perception under adverse listening conditions. Journal of Neuroscience, 27, 2283-2289. doi:10.1523/JNEUROSCI.4663-06.2007

Onifer, W., \& Swinney, D. A. (1981). Accessing lexical ambiguities during sentence comprehension: effects of frequency of meaning and contextual bias. Memory \& Cognition, 9, 225-236. doi:10.3758/BF03196957

Pattamadilok, C., Morais, J., Ventura, P., \& Kolinsky, R. (2007). The locus of the orthographic consistency effect in auditory word recognition: further evidence from French. Language and Cognitive Processes, 22, 700-726. doi:10.1080/01690960601049628

Patterson, K., \& Lambon Ralph, M. A. (2015). The Hub-and-Spoke hypothesis of semantic memory. In G. Hickok \& S. L. Small (Eds.), Neurobiology of Language. (pp.765-775). USA: Academic Press. doi:10.1016/B978-0-12-407794-2.00061-4

Patterson, K., Nestor, P. J., \& Rogers, T. T. (2007). Where do you know what you know? The representation of semantic knowledge in the human brain. Nature Reviews Neuroscience, 8 , 976-987. doi:10.1038/nrn2277 
Pelli, D. G., Palomares, M., \& Majaj, N. J. (2004). Crowding is unlike ordinary masking: distinguishing feature integration from detection. Journal of Vision, 4, 1136-1169. doi:10.1167/4.12.12

Pelli, D. G., \& Tillman, K. a. (2008). The uncrowded window of object recognition. Nature Neuroscience, 11, 1129-1135. doi:10.1038/nn1208-1463b

Perea, M., \& Gomez, P. (2012). Increasing interletter spacing facilitates encoding of words. Psychonomic Bulletin and Review, 19, 332-338. doi:10.3758/s13423-011-0214-6

Perfetti, C. A., \& Roth, S. (1981). Some of the interactive processes in reading and their role in reading skill. In A. Lesgold \& C. Perfetti (Eds.), Interactive processes in reading (pp. 269297). Hillsdale, NJ: Erlbaum.

Perry, C., Ziegler, J.C., \& Zorzi, M. (2006). Nested incremental modeling in the development of computational theories: the CDP+ model of reading aloud. Psychological Review, 114, 273 315. doi:10.1037/0033-295X.114.2.273

Perry, C., Ziegler, J. C., \& Zorzi, M. (2010). Beyond single syllables: large-scale modeling of reading aloud with the Connectionist Dual Process (CDP++) model. Cognitive Psychology, 61, 106-151. doi:10.1016/j.cogpsych.2010.04.001

Price, C. J. (2012). A review and synthesis of the first 20 years of PET and fMRI studies of heard speech, spoken language and reading. NeuroImage, 62, 816-847. doi:10.1016/j.neuroimage.2012.04.062

Rumelhart, D. E., \& McClelland, J. L. (1982). An interactive activation model of context effects in letter perception: II. The contextual enhancement effect and some tests and extensions of the model. Psychological Review, 89, 60-94. doi:10.1037/0033-295X.89.1.60

Schuberth, R. E., \& Eimas, P. D. (1977). Effects of context on the classification of words and nonwords. Journal of Experimental Psychology: Human Perception and Performance, 3, 27-36. doi:10.1037/0096-1523.3.1.27 
Schuberth, R. E., Spoehr, K. T., \& Lane, D. M. (1981). Effects of stimulus and contextual information on the lexical decision process. Memory \& Cognition, 9, 68-77. doi:10.3758/BF03196952

Seidenberg, M. S., Tanenhaus, M. K., Leiman, J. M., \& Bienkowski, M. (1982). Automatic access of the meanings of ambiguous words in context: some limitations of knowledge-based processing. Cognitive Psychology, 14, 489-537. doi:10.1016/0010-0285(82)90017-2

Simpson, G. B., Lorsbach, T. C., \& Whitehouse, D. (1983). Encoding and contextual components of word recognition in good and poor readers. Journal of Experimental Child Psychology, 35, 161-171. doi:10.1016/0022-0965(83)90076-0

Snell, J., van Leipsig, S., Grainger, J., \& Meeter, M. (2018). OB1-reader: A model of word recognition and eye movements in text reading. Psychological Review, 125, 969-984. doi:10.1037/rev0000119

Stanovich, K. E. (1980). Toward an interactive-compensatory model of individual differences in the development of reading fluency. Reading Research Quarterly, 16, 32-71. doi:10.2307/747348

Stanovich, K. E. (1984). The interactive-compensatory model of reading: A confluence of developmental, experimental, and educational psychology. Remedial and Special Education, 5(3), 11-19. doi:10.1177/074193258400500306

Stanovich, K. E., \& West, R. F. (1979). Mechanisms of sentence context effects in reading: automatic activation and conscious attention. Memory \& Cognition, 7, 77-85. doi:10.3758/BF03197588

Steen-Baker, A. A., Ng, S., Payne, B. R., Anderson, C. J., Federmeier, K. D., \& Stine-Morrow, E. A. L. (2017). The effects of context on processing words during sentence reading among adults varying in age and literacy skill. Psychology and Aging, 32, 460-472. doi:10.1037/pag0000184 
Swinney, D. A. (1979). Lexical access during sentence comprehension: (re)consideration of context effects. Journal of Verbal Learning and Verbal Behaviour, 18, 645-659. doi:10.1016/S0022-5371(79)90355-4

Swinney, D. A., Onifer, W., Prather, P., \& Hirshkowitz, M. (1979). Semantic facilitation across sensory modalities in the processing of individual words and sentences. Memory \& Cognition, 7, 159-165. doi:10.3758/BF03197534

Van Orden, G.C. (1987). A ROWS is a ROSE: Spelling, sound, and reading. Memory and Cognition, 15, 181-198. doi:10.3758/BF03197716

West, R. F., \& Stanovich, K. E. (1978). Automatic contextual facilitation in readers of three ages. Child Development, 49, 717-727. doi:10.2307/1128240

Whitney, D., \& Levi, D. M. (2011). Visual crowding: A fundamental limit on conscious perception and object recognition. Trends in Cognitive Sciences, 15, 160-168. doi:10.1016/j.tics.2011.02.005

Ziegler, J. C., \& Ferrand, L. (1998). Orthography shapes the perception of speech: the consistency effect in auditory word recognition. Psychonomic Bulletin and Review, 5, 683-689. doi:10.3758/BF03208845

Ziegler, J. C., Ferrand, L., \& Montant, M. (2004). Visual phonology: the effects of orthographic consistency on different auditory word recognition tasks. Memory and Cognition, 32, 732741. doi:10.3758/BF03195863

Ziegler, J. C., \& Goswami, U. (2005). Reading acquisition, developmental dyslexia, and skilled reading across languages: a psycholinguistic grain size theory. Psychological Bulletin, 131, 3-29. doi:10.1037/0033-2909.131.1.3

Zwitserlood, P. (1989). The locus of the effects of sentential-semantic context in spoken-word processing. Cognition, 32, 25-64. doi:10.1016/0010-0277(89)90013-9 
Table 1

Example of Sentence Contexts that were Congruent or Incongruent in Relation to the Visually Presented Target Word

\begin{tabular}{ll}
\hline Auditory sentence context & Target word \\
\hline $\begin{array}{l}\text { En el convento viven las... } \\
\text { (In the convent live the...) }\end{array}$ & $\begin{array}{l}\text { monjas / ruedas } \\
\text { (nuns)/ (wheels) }\end{array}$ \\
$\begin{array}{l}\text { Normalmente una bicicleta tiene dos... } \\
\text { (Normally a bicycle has two...) }\end{array}$ & $\begin{array}{l}\text { ruedas / monjas } \\
\text { (wheels)/ (nuns) }\end{array}$ \\
\hline
\end{tabular}


Table 2

Mean Reaction Time (ms) and Accuracy Data for LDT-no Context and LDT-Auditory Context, Standard deviation in parenthesis

\begin{tabular}{|c|c|c|c|c|}
\hline \multirow[b]{2}{*}{ Task } & \multicolumn{2}{|c|}{ Reaction times (ms) } & \multicolumn{2}{|c|}{ Mean accuracy (\%) } \\
\hline & $\begin{array}{l}\text { Words } \\
M(S D)\end{array}$ & $\begin{array}{l}\text { Pseudowords } \\
M(S D)\end{array}$ & $\begin{array}{l}\text { Words } \\
M(S D)\end{array}$ & $\begin{array}{l}\text { Pseudowords } \\
M(S D)\end{array}$ \\
\hline \multicolumn{5}{|c|}{ LDT-auditory context } \\
\hline \multicolumn{5}{|c|}{ Congruent sentence } \\
\hline Uncrowded & $534.18(94.14)$ & & $99.62(1.13)$ & \\
\hline Crowded & $556.59(88.56)$ & & $99.17(1.73)$ & \\
\hline \multicolumn{5}{|c|}{ Incongruent sentence } \\
\hline Uncrowded & 639.49 (115.17) & & $94.48(8.25)$ & \\
\hline Crowded & $677.59(119.81)$ & & $92.14(9.37)$ & \\
\hline \multicolumn{5}{|c|}{ LDT-no context } \\
\hline Uncrowded & $620.45(119.48)$ & $787.52(241.35)$ & $98.68(1.56)$ & $95.26(5.82)$ \\
\hline Crowded & $641.18(105.34)$ & $806.04(239.93)$ & $97.66(2.77)$ & $95.44(6.19)$ \\
\hline
\end{tabular}


Table 3

Reading Assessment Means and Medians Based on Accurate Words per Minute, Standard Deviation in Parentheses

Mean Median

Meaningful text

$160.10(21.83) \quad 158.00$

Meaningless text

$157.46(26.38) \quad 160.00$ 


\section{abejas}

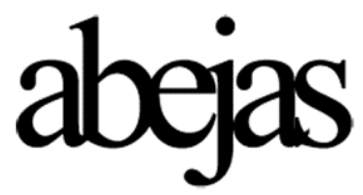

Figure 1. Example of an uncrowded target word with standard letter spacing (left) and a crowded target word with decreased letter spacing (right), according to Microsoft Office settings. 


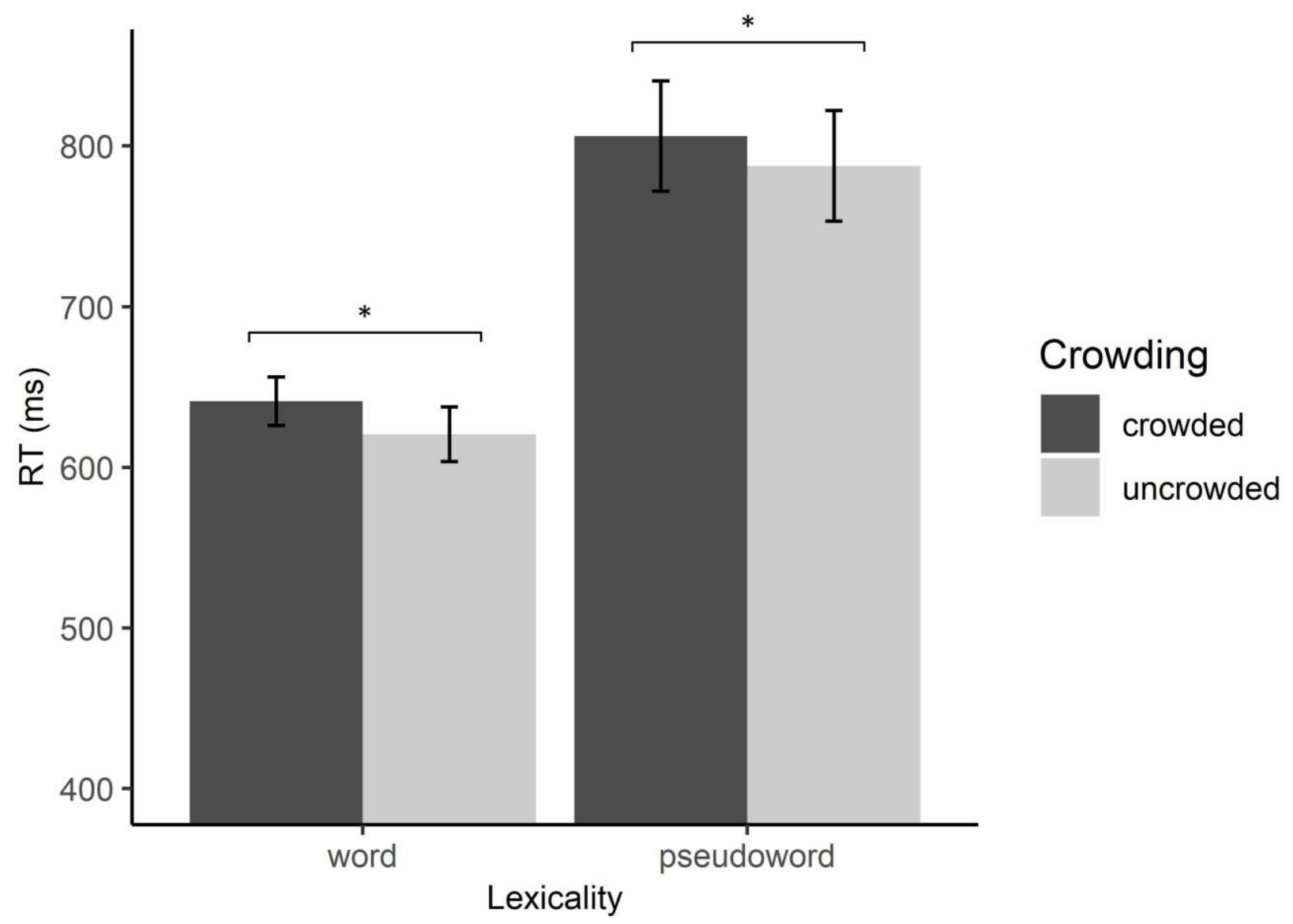

Figure 2. LDT-no context, mean reaction times on correct responses only. The effects of crowding on words and pseudowords, error bars represent SEM 


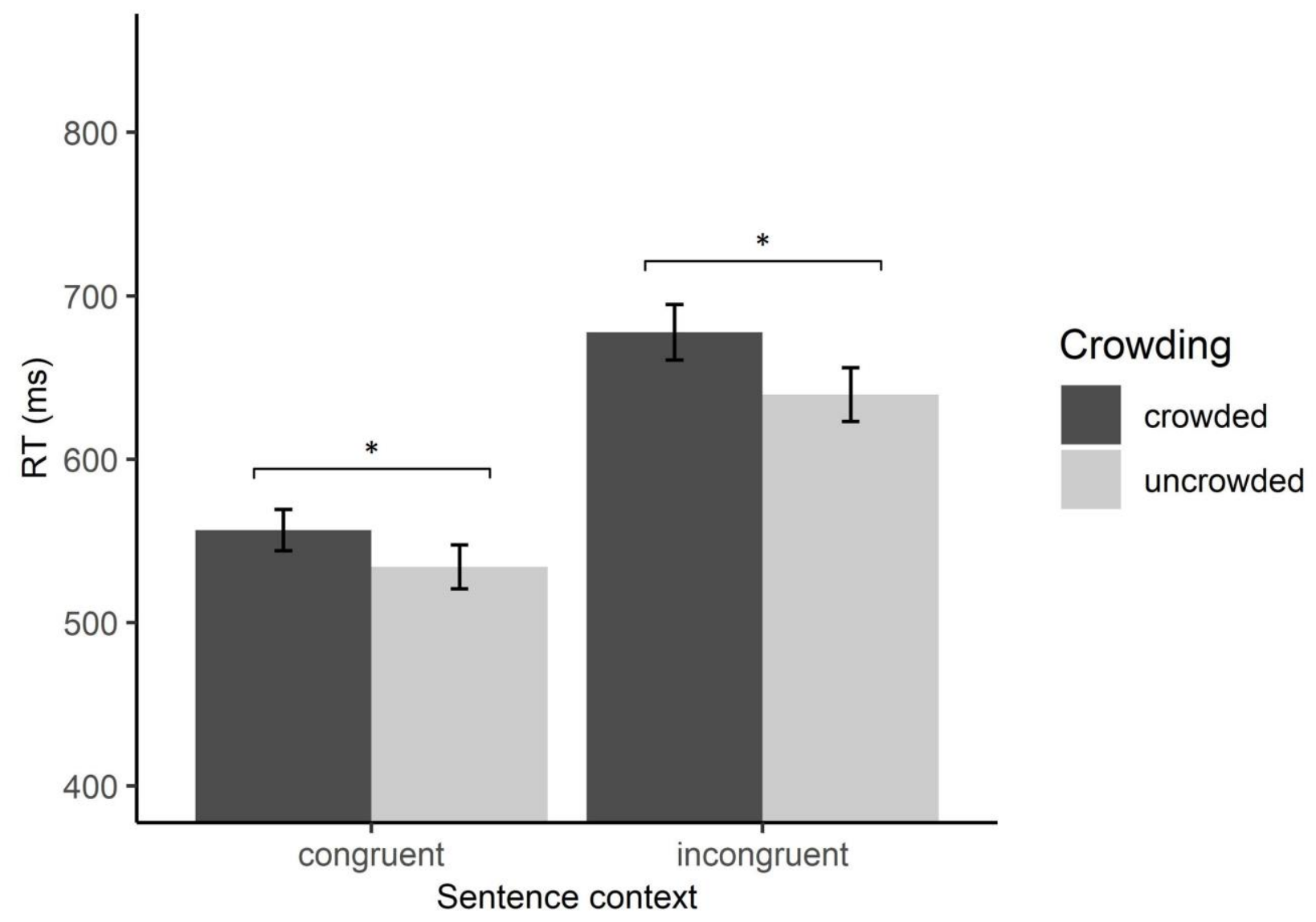

Figure 3. LDT-auditory context, mean reaction times on correct responses only. The effect of an auditory sentence context on crowded and uncrowded words, error bars represent SEM 
a

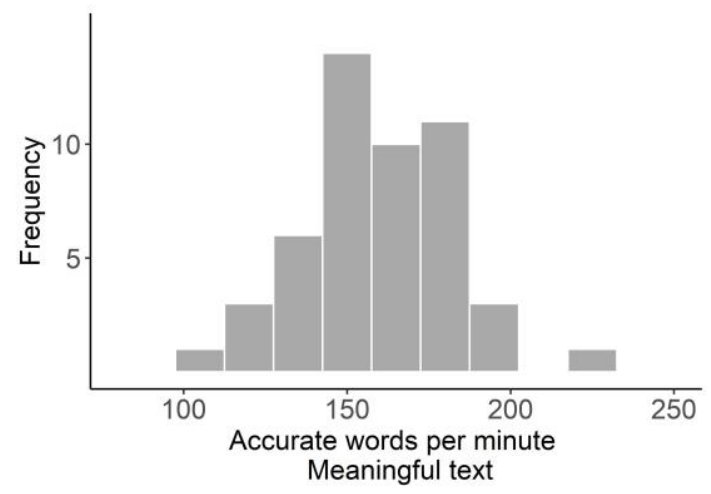

b

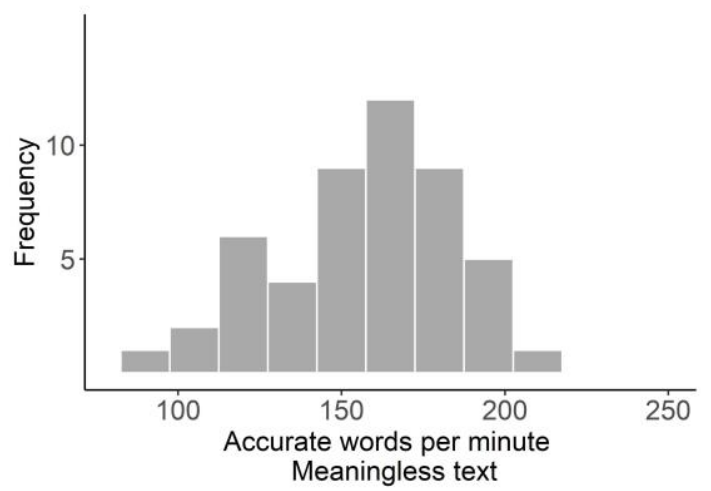

Figure 4. Reading fluency distribution of our sample, as calculated by accurate words read per minute on the meaningful text (a) and meaningless text (b) 